\title{
Changes in Earth's Energy Flows and Clouds in 228-Year Simulation with a High-Resolution AGCM
}

\author{
Masato Sugi
}

Received: 13 June 2011/ Accepted: 5 February 2012 / Published online: 14 March 2012

(C) The Author(s) 2012. This article is published with open access at Springerlink.com

\begin{abstract}
We have examined long-term changes in Earth's energy flows at top of the atmosphere (TOA) and at Earth's surface (land and ocean) by using 228-year simulation of a high-resolution global atmosphere model, MRI-AGCM3.2. It is found that the net downward short wave (SW) radiation (absorbed solar radiation, ASR) at TOA significantly increases during twenty-first century in agreement with a previous study. However, in the present study, the reason for the change is an increase in clear sky SW absorption by increased water vapor in the atmosphere, while it is a decrease in cloud amount in the previous study. It is also found that the long wave (LW) cloud radiative forcing for atmosphere is positive and increasing during twenty-first century in agreement with a previous study. The reason for the change in the present study is an increase in absorption by water vapor of the downward LW radiation emitted from clouds, while it is reductions of cloud amount in the middle troposphere in the previous study.
\end{abstract}

Keywords Earth's energy flow $\cdot$ Clouds $\cdot$ Climate change $\cdot$ High-resolution model

\section{Introduction}

The issue of how the radiative forcing induced by increased greenhouse gases (GHG) and aerosols changes the Earth's energy flows is one of the most important issues to understand the recent and future climate change. Trenberth and Fasullo (2009) (hereafter TF09) examined long-term changes in the Earth's energy flows at top of the atmosphere (TOA) by using Third Coupled Model Intercomparison Project (CMIP3) models. They found that the absorbed solar radiation (ASR) will significantly increase during twenty-first century under the A1B emission scenario mainly due to decreasing cloud amounts. They further pointed out that there is a large uncertainty in the projected changes in energy flow due to the large uncertainty in the clouds in the CMIP3 models.

M. Sugi (ه)

Japan Agency for Marine-Earth Science and Technology, Yokohama, Kanagawa-ken, Japan

e-mail: msugi@jamstec.go.jp 
The change in energy flows at TOA is the change in energy input to the atmosphere and Earth's surface (land and ocean). Another important issue is how this energy input is partitioned into the atmosphere and the Earth's surface. Particularly, the global hydrological cycle is expected to be strongly affected by the change in energy input to the atmosphere. The global precipitation is constrained by the energy balance of the atmosphere rather than the availability of moisture (Mitchell et al. 1987; Stephens et al. 1994; Allen and Ingram 2002; Sugi and Yoshimura 2004). It has been shown that the global precipitation will increase but the tropical circulation will become weaker in the future due to global warming (Sugi et al. 2002; Held and Soden 2006; Vecchi and Soden 2007).

Stephens and Ellis (2008) (hereafter SE08) examined the long-term change in global precipitation in CMIP3 models. They found that global precipitation efficiency is reduced by a negative cloud radiative heating feedback through reduction of cloud amount in the middle troposphere. To examine the change in atmospheric energy budget, we need to know the changes in energy flows at the Earth's surface as well in addition to the changes at TOA. In the present study, we examine the long-term changes in Earth's energy flows not only at TOA and but also at the Earth's surface by using a long-term simulation of a high-resolution global atmosphere model to study the long-term changes in atmospheric energy budget.

High-resolution models (horizontal resolution of about $100 \mathrm{~km}$ or higher) have been extensively used in some climate change studies, particularly in the studies of the climate change impact on tropical cyclones. One interesting finding regarding the tropical cyclone and climate change is a reduction of global tropical cyclone (TC) frequency in a future GHG warmed climate (Bengtsson et al. 1996; Sugi et al. 2002). Later, this reduction of TC frequency has been confirmed by many high-resolution model studies (Knutson et al. 2010). An interesting but yet disputable issue is the reason for the global TC reduction. Sugi et al. (2002) argued that the reduction of global TC frequency is closely related to a weakening of tropical circulation.

If the changes in tropical circulations are closely related to the change in global atmospheric energy budget, and if the changes in clouds significantly affect the change in atmospheric energy budget, then the uncertainty in the clouds among the various models may be responsible for the uncertainty in the changes in tropical circulations. In this regard, we are concerned about how the uncertainty in clouds in a model may affect the energy budget of the atmosphere. In the present study, therefore, we examine the role of clouds in terms of cloud radiative forcing (CRF) at TOA and at the surface.

A brief description of the high-resolution model and the long-term simulation is given at Sect. 2. The evolution of global mean energy fluxes at TOA and the Earth's surface, and the atmospheric heating due to the convergence of the energy fluxes, as well as the evolution of global mean CRFs are presented in Sect. 3.

Global annual maps of the energy fluxes and CRFs are presented in Sect. 4, followed by discussion and conclusion in Sects. 5 and 6, respectively.

\section{Model and Simulation}

The model we used for the 228-year simulation is a high-resolution (horizontal grid size of $60 \mathrm{~km}$ ) version of the new Meteorological Research Institute (MRI) Atmospheric General Circulation Model, MRI-AGCM3.2 (Mizuta et al. 2012). The model has 64 levels in the vertical with top at $0.01 \mathrm{hPa}$. The model was developed from the Japan Meterological Agency (JMA) Global Numerical Weather Prediction (NWP) Model (JMA, 2007) and 
shares many physical process subroutines, such as radiation scheme, PBL scheme, land surface scheme, and so on, with the NWP model, but some new physics schemes are incorporated. For MRI-AGCM3.2, we employed a new cumulus convection scheme developed by H. Yoshimura based on Tiedtke (1989) (Yukimoto et al. 2011). This convection scheme considerably improved the climatology of tropical convections. For the stratiform cloud scheme, Tiedtke (1993) cloud scheme is used. In this cloud scheme, cloud water and cloud amount are the prognostic variables. We do not use the subtropical marine stratocumulus scheme (Kawai and Inoue 2006) used in JMA NWP model. The direct effect of aerosols is calculated in the MRI-AGCM3.2, but indirect effect of aerosols is not considered in the present simulation.

The 228-year simulation was conducted using the $60-\mathrm{km}$ resolution version of the MRIAGCM3.2 with prescribed sea surface temperature (SST) and atmospheric concentration of greenhouse gas (GHG) including $\mathrm{CO}_{2}$ and aerosols. For the years from 1873 to 2003, the observed SST and sea-ice (HadISST1, Rayner et al. 2003) and observed GHG concentration (NASA, 2004) are prescribed. For the years from 2004 to 2099, the ensemble average SST increase projected by CMIP3 models are added to the de-trended observed SST from 1979 to 2003. In this procedure, the interannual variation of SST during 1979-2003 is repeatedly used. Similarly, the reduction of sea-ice is considered based on the ensemble average sea-ice change projected by CMIP3 models. The GHG and aerosols for the years 2004-2099 are based on the IPCC Special Report on Emission Scenario (SRES) A1B scenario. Aerosols from volcanic eruptions are not included except for the Mt. Pinatubo eruption in 1991.

Table 1 shows the simulated global mean energy flux components at TOA and the Earth's surface, averaged over 20-year period at the end of nineteenth, twentieth, and twenty-first century. The simulated energy fluxes at the end of twentieth century are generally in good agreement with observations (Trenberth et al. 2009). One of the largest differences between the simulation and observation is seen in the latent heat flux at the surface. The simulated value of latent heat flux is $85.6 \mathrm{~W} \mathrm{~m}^{-2}$ (corresponding to global mean precipitation of $2.95 \mathrm{~mm} /$ day), which is considerably larger than the value $80 \mathrm{~W} \mathrm{~m}^{-2}$ (precipitation of $2.76 \mathrm{~mm}$ /day) estimated from observation. We have also noted some systematic biases in the simulation of radiation fluxes at TOA (Figures not shown). The net downward short wave radiation (ASR) shows a distinct negative bias over the tropical ocean and positive bias at high latitudes, particularly over the southern oceans. These systematic biases in ASR are very similar to those of CMIP3 models (Trenberth and Fasullo 2010).

It should be noted that the 228-year simulation was not originally designed for the present study, and the experimental design may not be most suitable to study the changes in Earth's energy flows and clouds. However, the simulation provides us with a good opportunity to examine the long-term changes in Earth's energy flows and role of clouds in detail by using a high-resolution state-of-the-art atmospheric model.

\section{Evolution of the Global Annual Mean Energy Fluxes}

Figure 1 shows the changes from the end of nineteenth century in global annual mean downward energy fluxes at TOA and at the Earth's surface (land and ocean) and net heating of the atmosphere. Figure 1a shows the changes in downward energy fluxes at TOA. The net downward short wave (SW) radiation (ASR) changes very little during twentieth century and then increases at a rate about $2 \mathrm{~W} \mathrm{~m}^{-2} / 100$ years toward the end of twenty-first century. During the period from 1970 to 2020, the net downward long wave 
Table 1 Global mean energy fluxes averaged over 20 years at the end of nineteenth, twentieth and twentyfirst century

\begin{tabular}{lrrrrr}
\hline & \multicolumn{1}{l}{$19 \mathrm{C}$} & \multicolumn{1}{l}{$20 \mathrm{C}$} & \multicolumn{1}{c}{$21 \mathrm{C}$} & $20 \mathrm{C}-19 \mathrm{C}$ & 21C-19C \\
\hline DSWT & 341.3 & 341.3 & 341.3 & 0.0 & 0.0 \\
USWT & 101.8 & 101.9 & 100.0 & 0.1 & -1.8 \\
ULWT & 241.7 & 241.0 & 242.8 & -0.7 & 1.1 \\
DSWB & 194.2 & 193.5 & 191.0 & -0.7 & -3.2 \\
USWB & 30.9 & 30.4 & 28.3 & -0.5 & -2.6 \\
DLWB & 332.7 & 336.5 & 355.0 & 3.8 & 22.3 \\
ULWB & 396.2 & 398.7 & 412.5 & 2.5 & 16.3 \\
ULHB & 84.9 & 85.6 & 90.6 & 0.7 & 5.7 \\
USHB & 17.3 & 17.0 & 16.2 & -0.3 & -1.1 \\
NDSWT & 239.6 & 239.4 & 241.4 & -0.2 & 1.8 \\
NDLWT & -241.7 & -241.0 & -242.8 & 0.7 & -1.1 \\
NDFLXT & -2.2 & -1.5 & -1.4 & 0.7 & 0.8 \\
NDSWB & 163.4 & 163.2 & 162.7 & -0.2 & -0.7 \\
NDLWB & -63.5 & -62.2 & -57.5 & 1.3 & 6.0 \\
NDLHB & -84.9 & -85.6 & -90.6 & -0.7 & -5.7 \\
NDSHB & -17.3 & -17.0 & -16.2 & 0.3 & 1.1 \\
NDFLXB & -2.3 & -1.7 & -1.6 & 0.6 & 0.7 \\
AHSW & 76.2 & 76.2 & 78.7 & 0.0 & 2.5 \\
AHLW & -178.2 & -178.8 & -185.3 & -0.6 & -7.1 \\
AHLH & 84.9 & 85.6 & 90.6 & 0.7 & 5.7 \\
AHSH & 17.3 & 17.0 & 16.2 & -0.3 & -1.1 \\
\hline Uni is & & & & & \\
\hline
\end{tabular}

Unit is $\mathrm{Wm}^{-2}$. The right two columns show the changes from nineteenth century to twentieth century and twenty-first century, respectively

$D$ downward flux, $U$ upward flux, $N$ net downward flux (D-U), $S W$ short wave radiation, $L W$ long wave radiation, $S H$ sensible heat, $L H$ latent heat, $T$ top of the atmosphere (TOA), $B$ bottom of the atmosphere (surface), $F L X$ total flux, $A H$ atmospheric heating

(LW) radiation at $(-\mathrm{OLR})$ is larger than nineteenth century by about $0.7 \mathrm{~W} \mathrm{~m}^{-2}$ due to the increased greenhouse gases (GHG). Then, it decreases (i.e., OLR increases) toward the end of twenty-first century, as the temperature of the Earth's surface and atmosphere increases. From 1970 and afterward toward the end of twenty-first century, the net downward radiation at TOA $\left(R_{\mathrm{T}}\right)$ is about $0.7 \mathrm{~W} \mathrm{~m}^{-2}$ larger than that of nineteenth century, indicating a continuous warming of the Earth. Generally, the changes in ASR, -OLR, and $R_{\mathrm{T}}$ shown in Fig. 1a agree well with the changes of them shown in TF09 for CMIP3 models.

Figure 1b shows the changes in downward energy fluxes at surface. From 1980 and afterward, the downward LW radiation and the upward LH flux significantly increase. These two flux changes basically balance each other. There is a small decrease in downward SW radiation, which is almost balanced by the decrease in upward sensible heat flux. Note that throughout the twenty-first century the total net downward energy flux at the surface continues to be about $0.7 \mathrm{~W} \mathrm{~m}^{-2}$ larger than that of nineteenth century, indicating a continuous warming of the Earth's surface.

Figure 1c shows the changes in net heating of the atmosphere. During the twenty-first century, there is a significant increase in LW cooling, which is mainly balanced by a 
(a) Flux at TOA

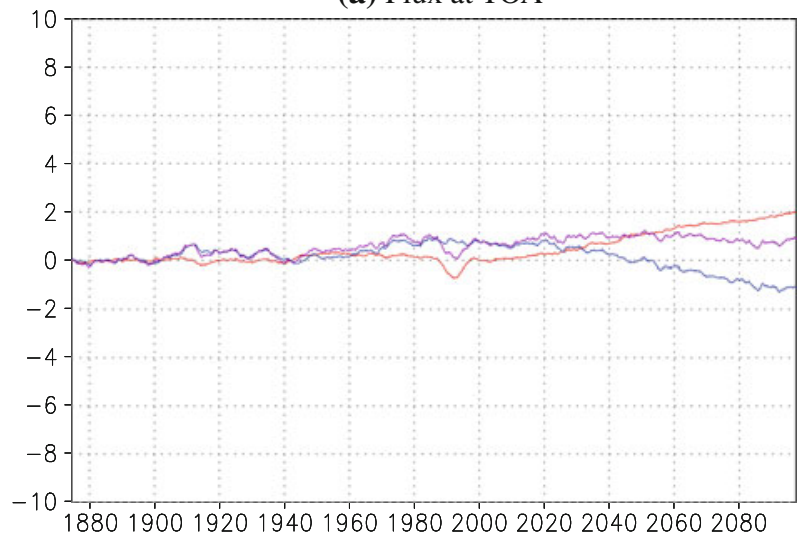

(b) Flux at surface

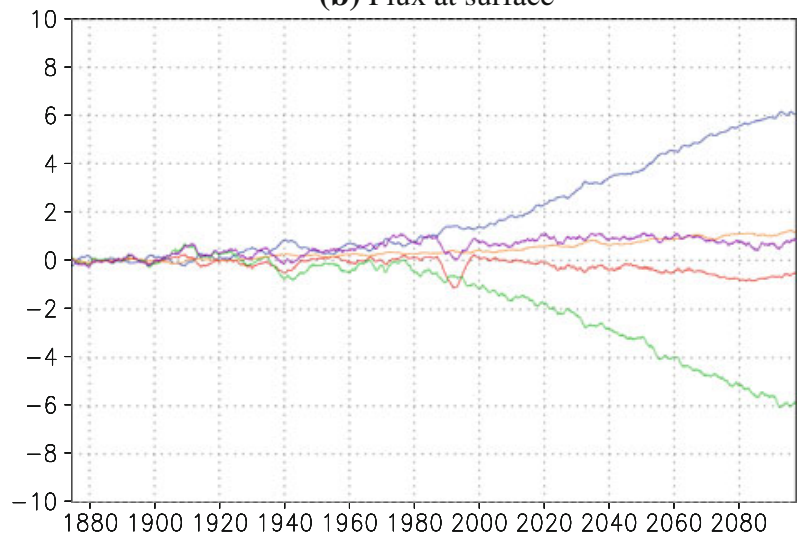

(c) Heating for atmosphere

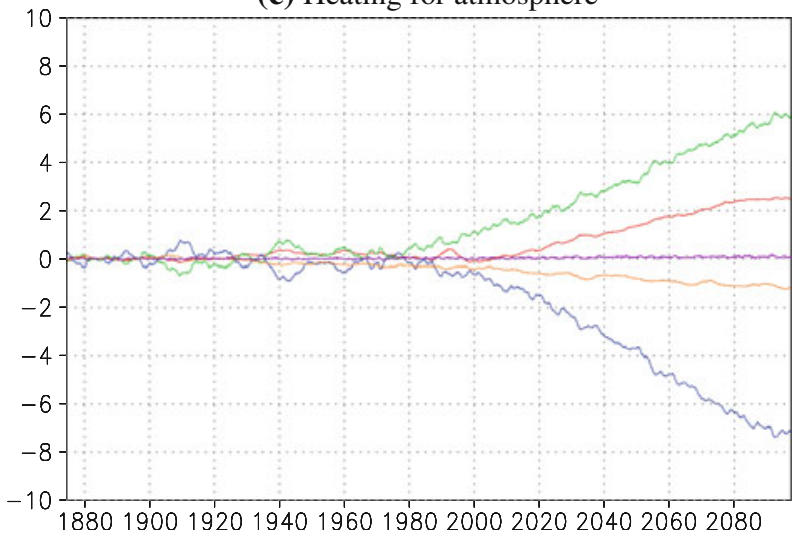

Fig. 1 Changes from the 20-year average at end of nineteenth century in global mean energy fluxes and heating of the atmosphere. Unit is $\mathrm{W} \mathrm{m}^{-2}$. a Net downward fluxes at top of the atmosphere. b Net downward fluxes at Earth's surface. $\mathbf{c}$ Net heating for the atmosphere. Red SW radiation, blue LW radiation, orange sensible heat, green latent heat, purple total energy flux or heating. Sixty-month running mean is applied for the curves to remove short time-scale variations 
significant increase in latent heating. In the atmospheric energy balance, however, the increase in solar heating due to the increase in atmospheric moisture is significant and it is larger than the decrease in SH heating, and it is playing some important role in the atmospheric energy balance.

Table 2 shows the globally averaged CRF at TOA and Earth's surface and for the atmosphere, averaged over 20 -year period at the end of nineteenth, twentieth, and twentyfirst century. CRF represents the cloud effect on radiation and is defined as the difference between net downward radiation with cloud $(R)$ and net downward clear sky radiation (CSR).

$$
\mathrm{CRF}=R-\mathrm{CSR}
$$

In the model, $R$ and CSR are calculated at each grid point by a double call to the radiation routine with and without clouds. In this calculation, the same water vapor profile is used for $R$ and CSR, and the water vapor effect of clouds is included as a part of cloud effect on radiation (Sohn and Bennartz 2008). Table 2 indicates that SW CRF at TOA is generally negative (cooling of atmosphere and surface), while LW CRF at TOA is generally positive (warming of atmosphere and surface). Table 2 also shows that SW CRF at surface is generally negative (cooling of surface), while LW CRF at surface is generally positive (warming of surface). On the other hand, both SW and LW CRF (cloud effect of radiative heating) for the atmosphere are generally positive (warming of atmosphere).

Figure 2 shows the changes from the end of nineteenth century in global annual mean cloud radiative forcing $(\triangle \mathrm{CRF})$ and clear sky radiation $(\triangle \mathrm{CSR})$. Note that the sum of $\triangle \mathrm{CRF}$ and $\Delta \mathrm{CSR}$ shown in Fig. 2 is equal to the changes in net downward radiation (or radiative heating of atmosphere) $\Delta R$ shown in Fig. 1.

$$
\Delta R=\Delta \mathrm{CRF}+\Delta \mathrm{CSR}
$$

Figure 2a shows the changes in CRF at TOA. During the twenty-first century, the negative SW CRF is increasing, indicating that the cooling effect of clouds is increasing toward the end of twenty-first century. On the other hand, LW CRF at TOA shows a slight decrease during twenty-first century, indicating that the warming effect of clouds is

Table 2 Global mean cloud radiative forcing (CRF) averaged over 20 years at the end of nineteenth, twentieth and twenty-first century

\begin{tabular}{lrrrrr}
\hline & \multicolumn{1}{c}{$19 \mathrm{C}$} & \multicolumn{1}{c}{$20 \mathrm{C}$} & \multicolumn{1}{c}{$21 \mathrm{C}$} & $20 \mathrm{C}-19 \mathrm{C}$ & 21C-19C \\
\hline SWT & -43.3 & -43.3 & -44.8 & 0.0 & -1.5 \\
LWT & 25.1 & 24.8 & 24.6 & -0.2 & -0.5 \\
NETT & -18.2 & -18.5 & -20.2 & -0.2 & -2.0 \\
SWB & -47.2 & -47.1 & -48.5 & 0.1 & -1.3 \\
LWB & 21.9 & 21.4 & 20.0 & -0.6 & -1.9 \\
NETB & -25.3 & -25.8 & -28.5 & -0.5 & -3.2 \\
SWA & 3.9 & 3.8 & 3.7 & -0.1 & -0.2 \\
LWA & 3.2 & 3.5 & 4.6 & 0.3 & 1.4 \\
NETA & 7.0 & 7.3 & 8.3 & 0.2 & 1.3 \\
\hline
\end{tabular}

Unit is $\mathrm{Wm}^{-2}$. The right two columns show the changes from nineteenth century to twentieth century and twenty-first century, respectively

$S W$ short wave radiation, $L W$ long wave radiation, $N E T$ net radiation, $T$ CRF at top of the atmosphere (TOA), $B \mathrm{CRF}$ at bottom of the atmosphere (surface), $A \mathrm{CRF}$ for the atmosphere 
(a) CRF at TOA

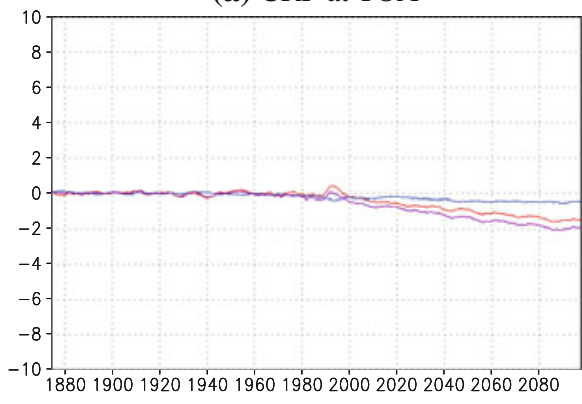

(b) CRF at surface

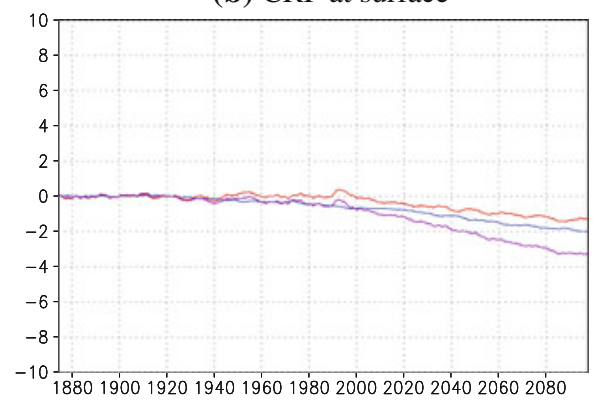

(c) CRF for atmosphere

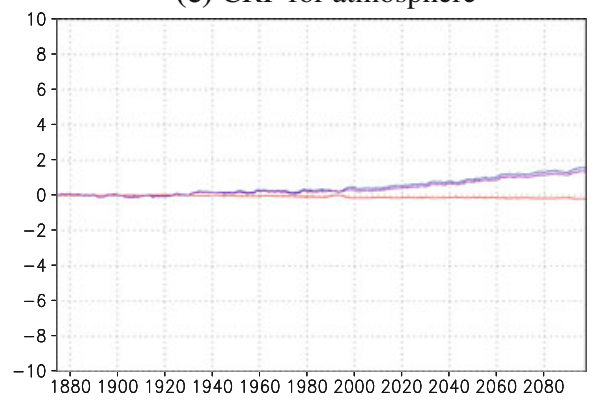

(d) CSRat TOA

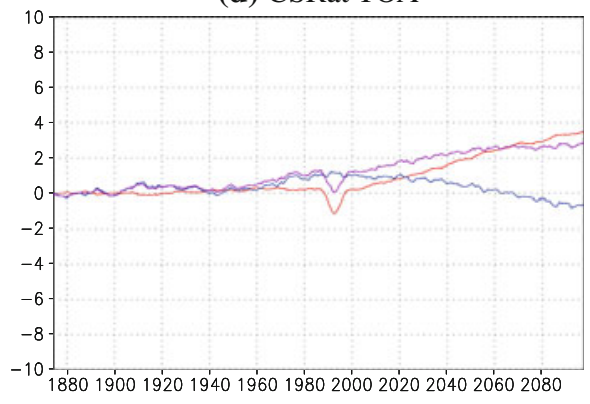

(e) CSR at surface

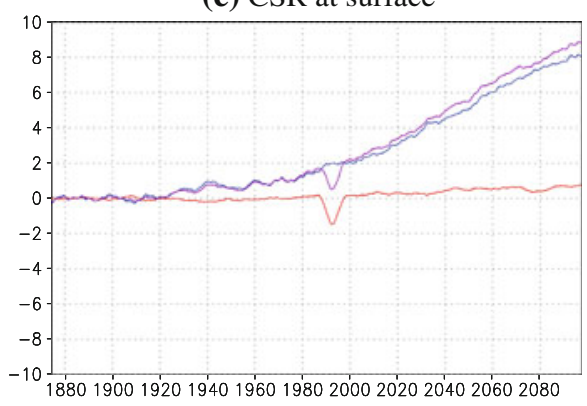

(f) CSR for atmosphere

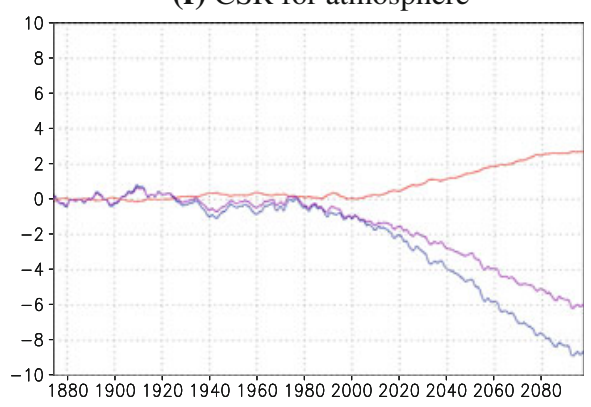

Fig. 2 Changes from the 20-year average at end of nineteenth century in global mean cloud radiative forcing (CRF) and clear sky radiation (CSR). Unit is $\mathrm{W} \mathrm{m} \mathrm{m}^{-2}$. a CRF at top of the atmosphere. b CRF at Earth's surface. $\mathbf{c}$ CRF for the atmosphere. d CSR at top of the atmosphere. e CSR at Earth's surface. f CSR for the atmosphere. Red SW, blue LW, purple net radiation CRF. Sixty-month running mean is applied for the curves to remove short time-scale variations

decreasing. Figure $2 b$ shows the changes in CRF at the Earth's surface. SW CRF shows almost the same decrease as the decrease at TOA, while LW CRF shows a much larger decrease than that at TOA. Figure $2 \mathrm{c}$ shows the changes in CRF for the atmosphere (CRF at TOA minus CRF at surface), which represents the cloud effect of heating the atmosphere. For SW radiation, as the changes in CRF at TOA and CRF at surface are almost the same, the changes in SW CRF for the atmosphere are very small. On the other hand, for LW radiation, as there is much more decrease in CRF at surface than at TOA, LW CRF for the atmosphere (cloud effect of atmospheric radiative heating) is significantly increasing, and it is playing some important role in the global atmospheric energy balance. The small 

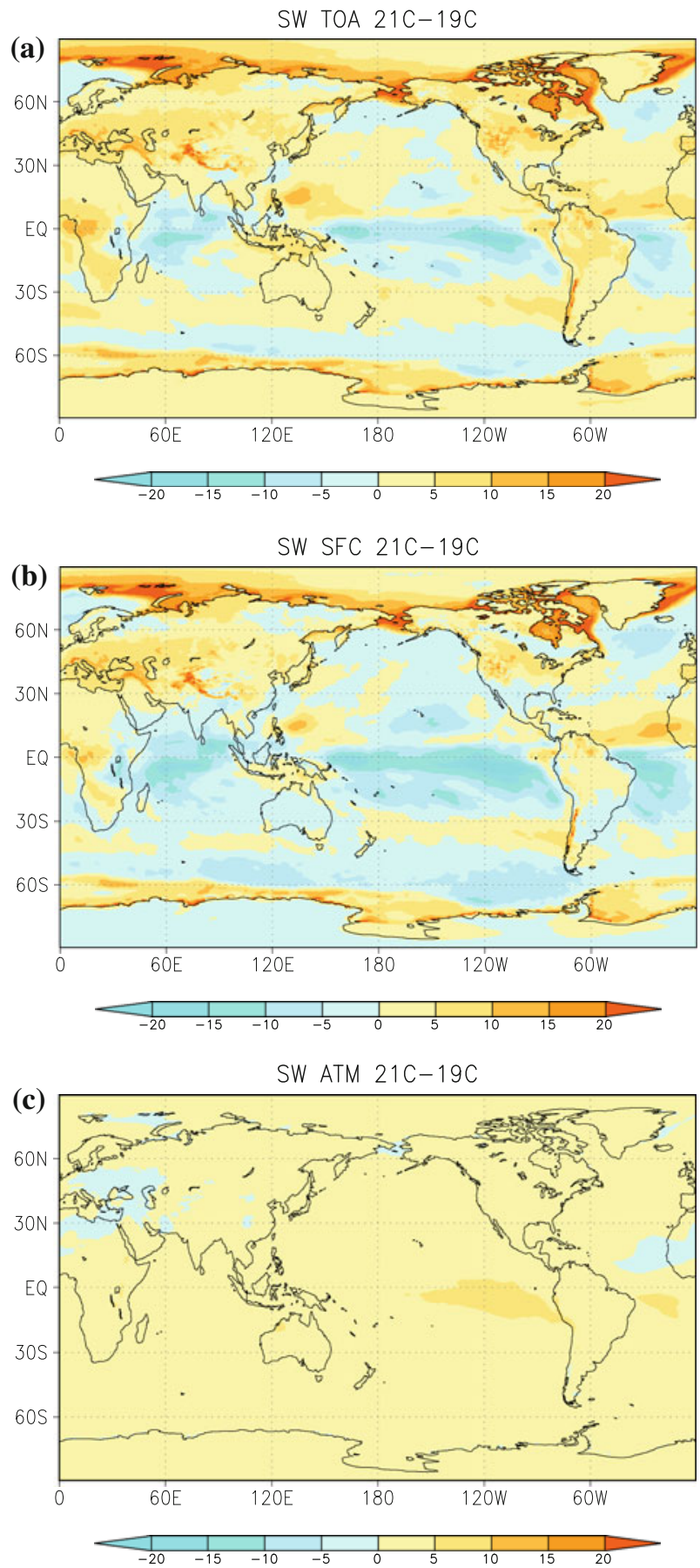

Fig. 3 Global maps of the changes from nineteenth to twenty-first century in annual mean SW radiation. Unit is $\mathrm{W} \mathrm{m} \mathrm{m}^{-2}$. a Net downward SW radiation at TOA. b Net downward SW radiation at surface. c Net SW heating of the atmosphere 

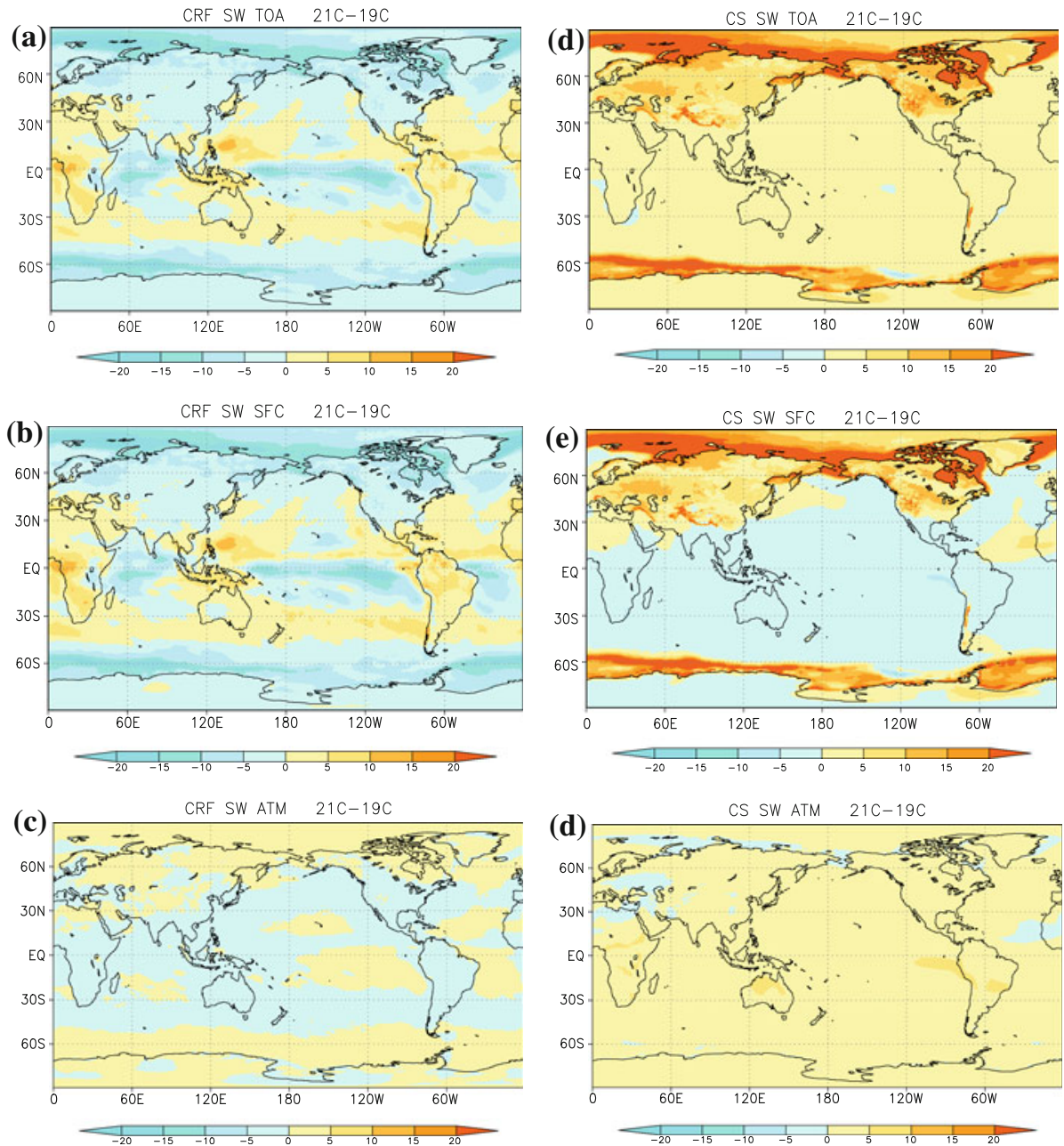

Fig. 4 Global maps of the changes from nineteenth to twenty-first century in annual mean SW CRF and SW CSR. Unit is $\mathrm{W} \mathrm{m}^{-2}$. a SW CRF at TOA. b SW CRF at surface. c SW CRF for the atmosphere. d SW CSR at TOA. e SW CSR at surface. $\mathbf{f}$ SW CSR for the atmosphere

change in SW CRF for the atmosphere and the significant increase in LW CRF for the atmosphere are consistent with the results of SE08.

Figure $2 \mathrm{~d}$ shows the changes in CSR at TOA. During the twenty-first century, the SW CSR shows larger increase compared with the decrease in the SW CRF. This indicates that the change in SW radiation at TOA is dominated by the change in CSR (water vapor effect) rather than the change is CRF (cloud effect). Similarly, the change in LW radiation at TOA is also dominated by the change in CSR (water vapor effect) rather than the change in CRF (cloud effect). Figure 2e shows the changes in CSR at surface. During the twenty-first century, the SW CSR shows only a small increase, while the LW CSR shows a very large increase due to the increased GHG and water vapor. Figure $2 \mathrm{f}$ shows the changes in CSR for the atmosphere. Figures $1 \mathrm{c}$ and $2 \mathrm{c}, \mathrm{f}$ indicate that both SW and LW heating of the atmosphere are dominated by CSR. The change in SW cloud effect on the atmosphere is 
LW TOA 21C-19C
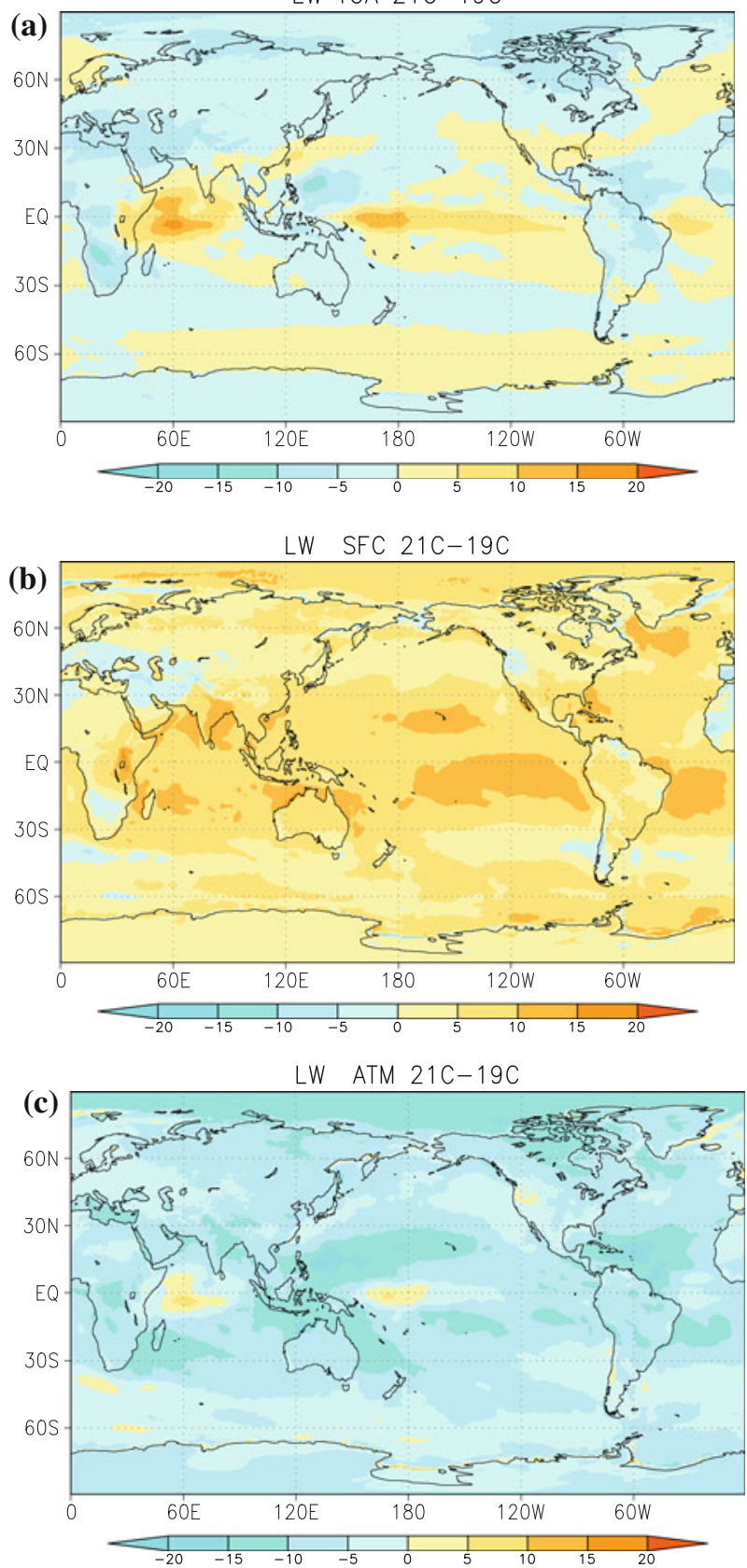

Fig. 5 Global maps of the changes from nineteenth to twenty-first century in annual mean LW radiation. Unit is $\mathrm{W} \mathrm{m}^{-2}$. a Net downward LW radiation at TOA. b Net downward LW radiation at surface. $\mathbf{c}$ Net $\mathrm{LW}$ heating of the atmosphere 

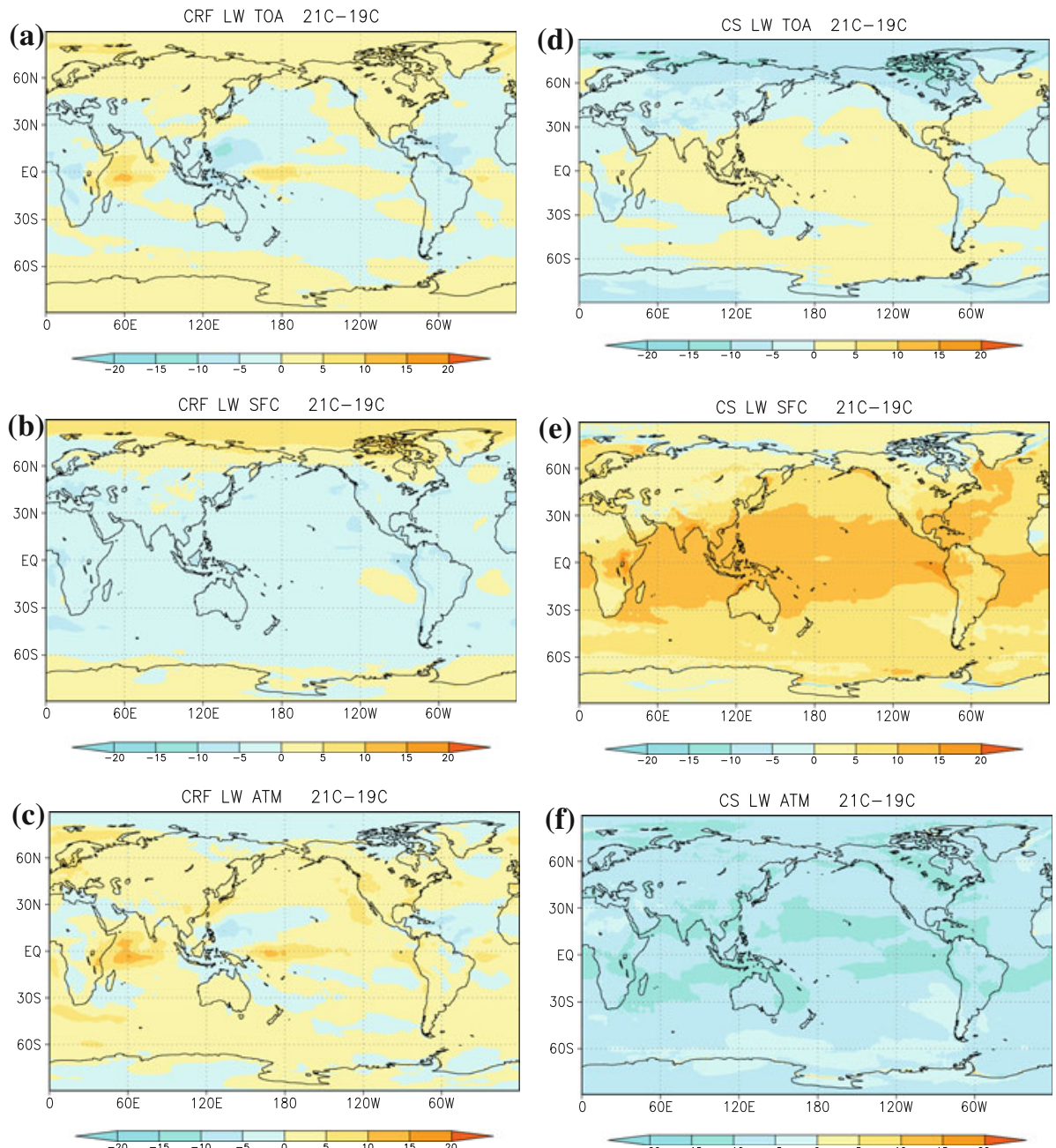

Fig. 6 Global maps of the changes from nineteenth to twenty-first century in annual mean LW CRF and LW CSR. Unit is $W m^{-2}$. a LW CRF at TOA. b LW CRF at surface. $\mathbf{c}$ LW CRF for the atmosphere. d LW CSR at TOA. e LW CSR at surface. $\mathbf{L W}$ CSR for the atmosphere

very small, while the LW cloud effect of warming of atmosphere is increasing during the twenty-first century.

\section{Global Maps of the Changes in Annual Mean Energy Fluxes}

Figure $3 \mathrm{a}-\mathrm{c}$ shows global maps of the changes from the end of nineteenth century in the annual mean downward radiation fluxes (a) at TOA, (b) at the Earth's surface (land and ocean), and (c) absorbed SW radiation by the atmosphere. The pattern of changes in SW radiation at TOA and surface are very similar to each other. The pattern also agrees with that shown by TF09. We can see a significant decrease of net downward SW radiation 
(increase of reflected SW radiation) at the tropical ocean region. This change is a result of the change in clouds (see Fig. 4). On the other hand, we can see a significant increase of net downward solar radiation (decrease of reflected solar radiation) at the polar sea-ice region, corresponding to a significant decrease of the sea-ice in twenty-first century. As shown in Fig. 3c, the change in the solar radiation absorbed by the atmosphere is rather uniform and weak positive. This indicates that a more SW radiation is absorbed by the overall increased atmospheric water vapor in twenty-first century.

Figure 4a-c shows the changes in SW CRF (a) at TOA, (b) at Earth's surface, and (c) for the atmosphere (cloud effect on SW atmospheric heating). The pattern of the changes in SW CRF at TOA and SW CRF at surface are very similar to each other. As a result, the SW CRF for the atmosphere, which is simply CRF at TOA minus CRF at surface, is generally small, in agreement with the result of SE08. This is because the major SW effect of clouds is reflection of solar radiation, and there is not so much contribution to the atmospheric heating, at least compared with the LW effect of clouds (see Fig. 2c). The negative SW CRF at TOA and surface is most significantly increasing over the equatorial
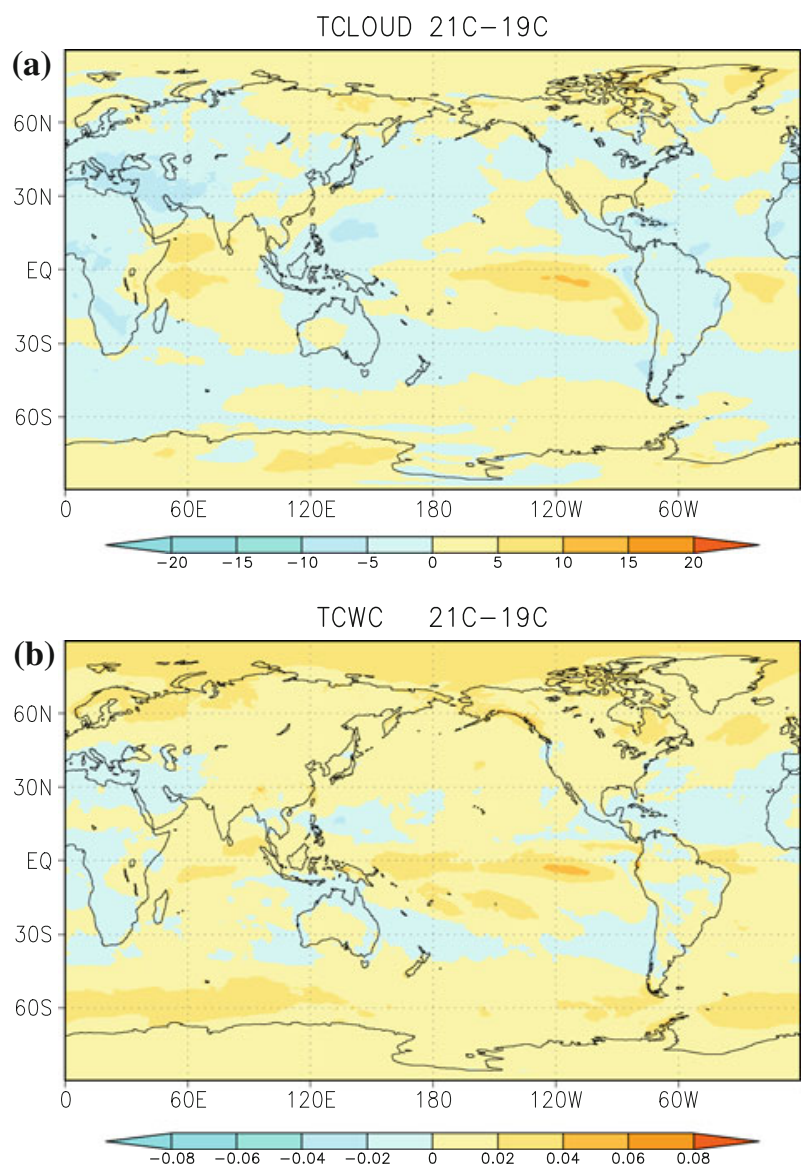

Fig. 7 Global maps of the changes from nineteenth to twenty-first century in annual mean column total cloud amount and column total cloud water content. a Cloud amount. Unit is \%. b Cloud water content. Unit is $\mathrm{kg} \mathrm{m}^{-2}$ 
ocean regions and the polar sea-ice regions. On the other hand, we can see a region in the western North Pacific where the positive SW CRF is significantly increasing. This corresponds to a weakening of convections over this region (see next section for further discussion).

Figure 4d-f shows the changes in SW CSR (d) at TOA, (e) at Earth's surface, and (f) absorbed clear sky SW radiation by the atmosphere. In the polar sea-ice regions, as the effect of albedo decrease due to the reduction of sea-ice in summer (Fig. 4d, e) is larger than the effect of SW CRF change (Fig. 4a, b), the net downward SW radiation is increasing (Fig. 3a, b). Figure $4 \mathrm{f}$ shows a uniform warming of the atmosphere by clear sky $\mathrm{SW}$ radiation due to increased water vapor.

Figure 5a-c shows global maps of the changes from the end of nineteenth century in the annual mean net downward LW radiation (a) at TOA and (b) at Earth's surface, and (c) absorbed LW radiation by the atmosphere. The pattern of the change is generally in good agreement with that shown by TF09. We can see a decrease in net downward LW at TOA (increase of OLR) in most regions except for tropical oceans and Southern Ocean. The decrease of OLR over the tropical ocean corresponds well to the increase in clouds over the same region (see Fig. 6). As shown in Fig. 5b, c, the changes in net downward LW radiation at surface are mostly positive (warming of the surface), and the changes in absorbed LW radiation by the atmosphere are mostly negative (cooling of the atmosphere). These increases in surface warming and atmospheric cooling are simply due to the enhanced greenhouse effect by the increased GHG and water vapor. Note that there are small regions where the change in LW absorption is positive in equatorial Indian Ocean and equatorial western Pacific in Fig. 5c. These regions correspond to the regions where the change in LW cloud effect of warming the atmosphere is increasing (see Fig. 6c).

Figure 6a-c shows the changes in LW CRF (a) at TOA and (b) at surface, and (c) for the atmosphere (cloud effect on LW atmospheric heating). In the low and mid latitudes, LW CRF at TOA is generally decreasing except for equatorial ocean regions, where the LW cloud effect of warming is increasing. It should be noted that the pattern of the changes in LW CRF at TOA is similar (with opposite sign) to that of the changes in SW CRF at TOA (Fig. 4a), indicating that the changes in both SW and LW CRF at TOA are associated with the changes in clouds (see Fig. 7a). On the other hand, LW CRF at surface is rather uniformly decreasing (reduction of surface warming) except for the polar region, indicating that the changes in LW CRF at surface is not directly associated with the changes in clouds. This uniform decrease of the LW CRF at surface is probably due to the increased absorption by water vapor of the downward LW radiation emitted from high- and middle-level clouds. In the polar region, where there are not many high- and middle-level clouds, LW CRF at surface is increasing due to the increased low-level clouds. LW CRF for the atmosphere, which is equal to CRF at TOA minus CRF at surface, is generally increasing, with large increase over the equatorial ocean region and some decrease over the western North Pacific, tropical North Atlantic, and Arctic Ocean. This pattern of the changes in LW CRF for the atmosphere is generally in good agreement with SE08.

Figure 6d-f shows the changes in LW CSR (d) at TOA, (e) at Earth's surface, and (f) for the atmosphere (absorbed clear sky LW radiation by the atmosphere). Figure 6e, $\mathrm{f}$ shows significant increases in warming of the Earth's surface and cooling of the atmosphere due to the enhanced greenhouse effect by the increased GHG and water vapor. Note that the surface warming and atmospheric cooling are particularly large in the tropics where the water vapor increases most significantly. 


\section{Discussion}

The global mean energy flux components at TOA and Earth's surface, averaged over the 20 -year period at the end of nineteenth, twentieth and twenty-first century, are shown in Table 1 . The right two columns show the changes from nineteenth to twentieth century and from nineteenth to twenty-first century, respectively. The most significant changes from nineteenth to twenty-first century are the $22.3 \mathrm{~W} \mathrm{~m}^{-2}$ increase in downward $\mathrm{LW}$ flux at surface and $16.3 \mathrm{~W} \mathrm{~m}^{-2}$ increase in upward LW flux at surface. As a result, the net downward LW flux increases by $6 \mathrm{~W} \mathrm{~m}^{-2}$ and mostly balanced by the increase in upward LH flux. In the change in energy balance at the surface, the contribution from changes in SW flux and SH flux is small. On the other hand, in the change in energy balance of the atmosphere, the contribution from the increase in SW absorption is significant.

To further examine the role of clouds in the changes in Earth's energy flows, the globally averaged CRF at TOA, Earth's surface and for the atmosphere, averaged over 20 -year period at the end of nineteenth, twentieth and twenty-first century, are shown in Table 2. The magnitude of both the SW CRF and LW CRF reaches up to 10-30\% of the respective radiation fluxes, indicating significant roles of clouds in the Earth's energy flows. Generally, SW CRF at TOA and surface is negative (cooling the atmosphere and surface), while LW CRF is positive (warming the atmosphere and surface). However, as shown in Table 2, both SW and LW CRF for the atmosphere (defined as CRF at TOA minus CRF at surface) are positive (warming the atmosphere).
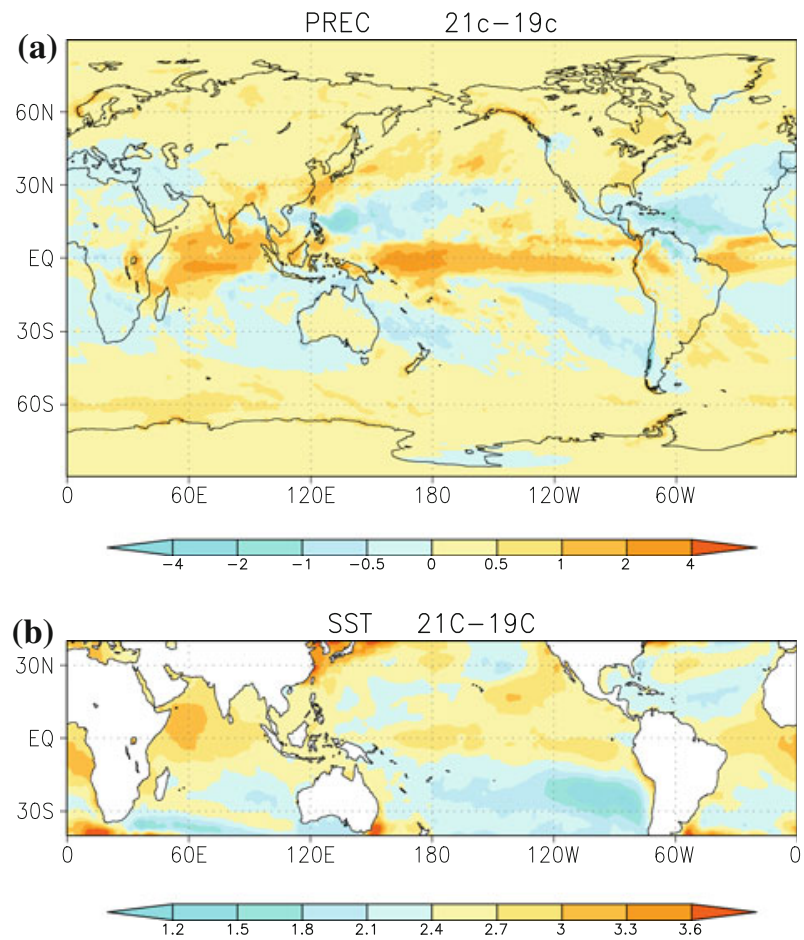

Fig. 8 Global maps of the changes from nineteenth to twenty-first century in annual mean precipitation and SST. a Precipitation. Unit is $\mathrm{mm} /$ day. b SST. Unit is ${ }^{\circ} \mathrm{C}$ 
Regarding the changes from nineteenth to twenty-first century, we note that SW CRF decreases (negative CRF increases) both at TOA and surface, resulting in small changes in CRF for the atmosphere. On the other hand, LW CRF decreases only a little at TOA but it decreases significantly at surface, resulting in a significant increase $\left(1.4 \mathrm{~W} \mathrm{~m}^{-2}\right)$ in CRF for the atmosphere (warming the atmosphere), which makes a significant contribution to the changes in the atmospheric energy balance.

Table 2 indicates that both the changes in globally averaged SW and LW CRF from nineteenth to twenty-first century are negative (cooling of atmosphere and surface is increasing). For SW CRF, this means the cloud effect (cooling) is increasing, but for LW $\mathrm{CRF}$, this means the cloud effect (warming) is decreasing. Are clouds indeed increasing or decreasing in the model? In Fig. 7, we show the global maps of the changes from the end of nineteenth century in the annual mean column total cloud amount and column total cloud water content. We note that the pattern of the changes in cloud amount (Fig. 7a) generally agrees well with the pattern of the changes in LW CRF at TOA (Fig. 6a). The regions where the negative SW CRF is increasing generally correspond to the regions where cloud amount is increasing. However, there are wide areas in mid latitudes where cloud amount is decreasing but negative SW CRF is increasing. In such regions, we can see that cloud water content is increasing. In these areas, the increased cloud water content may increase the reflectivity of clouds and increase the negative SW CRF even though the cloud amount is decreased.

We have seen that both the LW and SW cloud effect increases from nineteenth to twenty-first century over the equatorial ocean region, while they decrease over the western Pacific and tropical North Atlantic. These positive and negative changes are closely related to the changes in activity of tropical convection. The map of changes in precipitation associated with the changes in convective activity is shown in Fig. 8. In Fig. 8, the map of changes in SST is also shown. We note that there are large SST increases over the Indian Ocean and central to eastern tropical Pacific (corresponding to a weakening of the cold tongue), while a relatively small SST increase over the western Pacific regions. These figures clearly demonstrate that the distribution of clouds and precipitation associated with convection is dominated by the distribution of changes in relative SST. As we use the SST increase projected by CMIP3 models, it is reasonable that the patterns of the precipitation change, and therefore, the pattern of changes in clouds associated with the tropical convections in our simulation are in good agreement with those projected by CMIP3 models. Indeed, the pattern of the precipitation change shown in Fig. 8 resembles the pattern of the change in precipitation by CMIP3 models (Meehl et al. 2007).

\section{Conclusions}

We have examined long-term changes in Earth's energy flows at TOA and surface by using the 228-year simulation of a high-resolution atmospheric model, MRI-AGCM3.2. It is found that the net downward SW radiation at TOA (ASR) significantly increases during twenty-first century, while the net downward LW radiation at TOA (-OLR) first increases toward the end of twentieth century then starts decreasing at around year 2020. These changes in ASR and -OLR are generally in good agreement with the changes in CIMIP3 models shown by TF09. The patterns of the changes in the present study in ASR and -OLR and in cloud amount are also similar to those of TF09. However, the reason for the changes, particularly for the change in global mean ASR, is very different. TF09 indicates that the significant increase in ASR at TOA during twenty-first century is mainly due to the 
reduction of clouds. On the other hand, in the present study, as the negative SW CRF at TOA is increasing, the effect of clouds on SW radiation (CRF) is decreasing ASR, and the main reason for the increase in ASR is the increase in clear sky SW absorption by increased water vapor in the atmosphere. This seems to suggest that the same energy balance could be achieved in different ways in different climate models. The large increase in the absorbed SW radiation by atmospheric water vapor can affect the atmospheric energy balance and in turn the hydrological cycle as well.

In the present study, the changes in both SW and LW CRF are negative and increase toward the end of twenty-first century. This is considered to result from a decrease in cloud amount and an increase in cloud water content. As the changes in global mean SW CRF at TOA and at surface are almost the same, the change in SW CRF for the atmosphere is very small. On the other hand, as the negative change in global mean LW CRF at surface is much larger than that at TOA, the change in LW CRF for the atmosphere is significantly positive. The positive change of LW CRF for the atmosphere is consistent with the result of SE08 for CMIP3 models. Moreover, the pattern of changes in LW CRF for the atmosphere in the present study also resembles that of SE08. However, the reason for the changes may be different. SE08 indicated that the decrease of mid- and low-level cloud amount is the reason for the warming of the atmosphere. On the other hand, we found that LW CRF at surface is uniformly decreasing due to an increased absorption by water vapor of the downward LW radiation emitted from clouds, and this is the reason for the increase in LW CRF for the atmosphere (warming of the atmosphere).

As shown in Meehl et al. (2007), the change in CRF varies from negative to positive among the models. The long-term changes in energy flows and the role of clouds may be different among the models with different CRF changes. In our model, the change in both SW and LW CRF is negative (cloud feedback is negative). The conclusions of the present study are based on one model with negative cloud feedback, and they may be different in a model with positive cloud feedback. It is important to understand how the models with different cloud representation produce different responses to the GHG forcing. For this purpose, it is recommended to examine the long-term changes in energy fluxes and CRF both at TOA and at surface in various models.

Acknowledgments This work was conducted under the framework of the "Projection of the Change in future Weather Extremes using Super-high-resolution Atmospheric Models" supported by the KAKUSHIN Program of the Ministry of Education, Culture, Sports, Science, and Technology (MEXT). The calculations were performed on the Earth Simulator.

Open Access This article is distributed under the terms of the Creative Commons Attribution License which permits any use, distribution, and reproduction in any medium, provided the original author(s) and the source are credited.

\section{References}

Allen MA, Ingram WJ (2002) Constraints on future changes in climate and the hydrologic cycle. Nature 419:224-232. doi:10.1038/nature01092

Bengtsson L, Botzet M, Esch M (1996) Will greenhouse gas-induced warming over the next 50 years lead to higher frequency and greater intensity of hurricanes? Tellus 48A:57-73

Held IM, Soden BJ (2006) Robust responses of the hydrological cycle to global warming. J Clim 19:5686-5699

Kawai H, Inoue T (2006) A simple parameterization scheme for subtropical marine stratocumulus. SOLA 2:17-20. doi:10.2151/sola.2006-005 
Knutson T, McBride J, Chan J, Emanuel K, Holland G, Landsea C, Held I, Kossin JP, Srivastava A, Sugi M (2010) Tropical cyclones and climate change. Nat Geosci. doi:10.1038/ngeo0779

Meehl GA et al. (2007) Global climate projections, in Climate Change 2007: the physical science basis, contribution of working group I to the fourth assessment report of the intergovernmental panel on climate change. In: Solomon S et al (ed) Cambridge University Press, New York, pp 748-849

Mitchell JFB, Wilson CA, Cunnington WM (1987) On $\mathrm{CO}_{2}$ climate sensitivity and model dependence of results. Q J R Meteorol Soc 113:293-322

Mizuta R, Yoshimura H, Murakami H, Matsueda M, Endo H, Ose T, Kamiguchi K, Hosaka M, Sugi M, Yukimoto S, Kusunoki S, Kitoh A (2012) climate simulations using the improved MRI-AGCM with 20-km grid. J Meteorol Soc Jpn 90A:235-236

Rayner NA, Parker DE, Horton EB, Folland CK, Alexander LV, Rowell DP (2003) Global analysis of sea surface temperature, sea ice, and night marine air temperature since the late nineteenth century. J Geophys Res 108:4407

Sohn BJ, Bennartz R (2008) Contribution of water vapor to observational estimates of long wave cloud radiativa forcing. J Geophys Res 113:D20107

Stephens GL, Ellis TD (2008) Controls of global-mean precipitation increases in global warming GCM experiments. J Climate 21:6141-6155

Stephens G, Slingo A, Webb MJ, Minnett PJ, Daum PH, Kleiman L, Wittmeyer I, Randall DA (1994) Observations of the Earth's radiation budget in relation to atmospheric hydrology. 4. Atmospheric column radiative cooling over the worlds' oceans. J Geophys Res 99:18585-18604

Sugi M, Yoshimura J (2004) A mechanism of tropical precipitation change due to $\mathrm{CO}_{2}$ increase. $\mathrm{J}$ Clim $17: 238-243$

Sugi M, Noda A, Sato N (2002) Influence of the global warming on tropical cyclone climatology: an experiment with the JMA Global Model. J Meteorol Soc Jpn 80:249-272

Tiedtke M (1989) A comprehensive mass flux scheme for cumulus parameterization in large scale models. Mon Wea Rev 117:1779-1800

Tiedtke M (1993) Representation of clouds in large scale models. Mon Wea Rev 121:3040-3061

Trenberth KE, Fasullo JT (2009) Global warming due to increasing absorbed solar radiation. Geophys Res Lett 36:L07706. doi:10.1029/2009GL037527

Trenberth KE, Fasulo T, Kiehl J (2009) Earth's global energy budget. Bull Amer Soc 90:311-323

Trenberth KE, Fasullo JT (2010) Simulation of present-day and twenty-first-century energy budgets of the southern oceans. J Clim 23:440-454

Vecchi GA, Soden BJ (2007) Global warming and the weakening of the tropical circulation. J Clim $20: 4316-4340$

Yukimoto et al. (2011) Meteorological Research Institute-Earth System Model v1 (MRI-ESM1)—model description. Tech Rep Meteorol Res Inst 64:1-83 